\title{
Public Perceptions of Environmental Management in the Puget Sound Region
}

\author{
THOMAS G. SAFFORD, MATTHEW J. CUTLER, \\ MEGAN HENLY, KARMA C. NORMAN, AND PHILLIP S. LEVIN
}

$\longrightarrow$ onsistent with its public trust responsibilities, government is a central player in environmental concerns. Public-sector actors must balance human uses and interests with those of the environment when seeking solutions to environmental issues. In the Puget Sound region of Washington State, governmental entities are attempting to identify management approaches that strike a balance between social and environmental needs. To aid these efforts, researchers from the Carsey Institute and the National Oceanic and Atmospheric Administration (NOAA) Fisheries investigated public perceptions of different environmental interventions in Puget Sound.

We surveyed 1,980 residents of the Puget Sound Basin to better understand their views about potential environmental policy measures and to establish whether they believe existing regulations have benefited their community. ${ }^{1}$ Our findings show broad support for various types of environmental interventions (see Figure 1). These proposals include restricting boating and shipping activities to protect marine mammals such as killer whales and sea lions; more strongly enforcing existing environmental rules and regulations; spending government money to restore the environment for fish and wildlife; and providing tax credits to businesses that voluntarily reduce their environmental impact.

Figure 1. SUPPORT FOR ENVIRONMENTAL MANAgEMENT APPROACHES

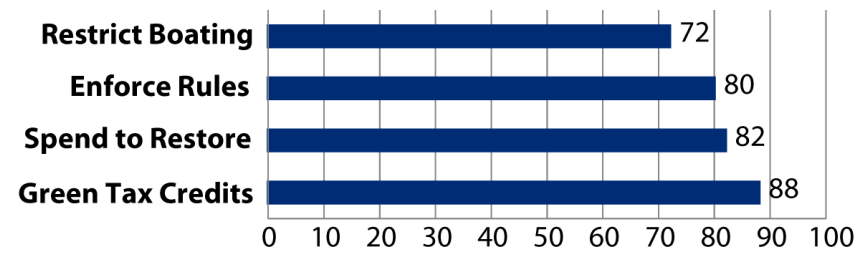

Percent in Favor of Environmental Proposals

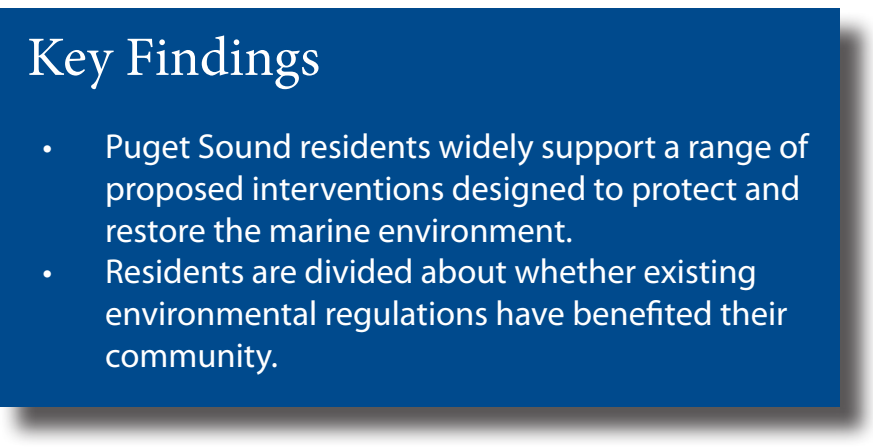

Each of these measures has the support of nearly threequarters of residents, with tax credits for "green" business practices gaining the widest support ( 88 percent) and restricting shipping to protect marine mammals the least (72 percent). These results suggest substantial backing for government-sponsored actions to protect and restore the Puget Sound environment. When looking specifically at development restrictions, the results were more mixed. Nearly one-half (46 percent) indicated that conservation or environmental rules that restrict development had generally been good for their community, 10 percent thought they had been bad, and the remaining 44 percent thought they had either had no effect or they were unsure about their impact.

Additional survey data show that public opinion also differs depending on where one lives (rural, urban, or suburban locale) and level of education (see Figures 2A and 2B). Urban residents and those with higher levels of education were more likely than others to consider existing environmental restrictions on development as being good for their community (see Figure 2A). Residents of suburban areas, where the greatest amount of development has occurred, are significantly less likely than urbanites to view conservation rules as a good thing for their community. These findings could reflect the importance of housing development within the suburban economy or concern that regulations have 
Figure 2A. EFFeCt Of ENVIronMental RULES by PLACE OF RESIDENCE
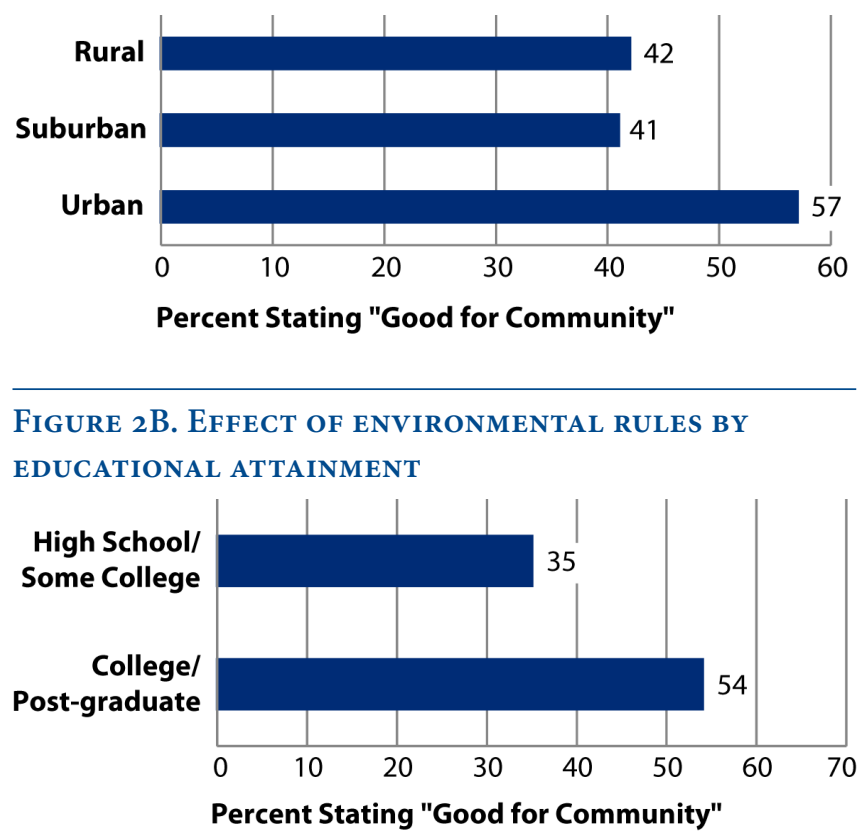

inhibited needed growth. Similarly, the decreased likelihood that individuals who have completed only high school or some college courses see conservation rules as good for their community may indicate apprehension about the economic implications of restrictions on development, which generates needed jobs in sectors such as construction (see Figure 2B). ${ }^{2}$

Governmental actors working to develop socially acceptable environmental policies face a challenging endeavor. Our research shows that most residents of the Puget Sound region favor a variety of new interventions to address environmental concerns. Nonetheless, when attributing benefits to their community from existing regulations, residents are more circumspect, and there are marked differences of opinion across urban, suburban, and rural areas, as well as based on level of education.

These results offer important insights for policymakers and natural resource managers confronting environmental problems. Opposition to actions that address environmental concerns is relatively low in Puget Sound. However, ensuring broad public support will likely hinge on understanding why many residents, and in particular those with only a high school education and living outside of urban areas, do not see existing regulations as a good thing for their community. By uncovering these trends, social scientists can aid policymakers attempting to develop socially and environmentally acceptable interventions.
E N D N O T ES

1. The UNH Survey Center administered a random digit dial phone survey to 1,980 residents of King, Kitsap, Mason, Pierce, Skagit, and Whatcom counties in two waves between January and February 2012 and July and August 2012. Data were weighted to make slight adjustments for non-response by age, race, and sex and to adjust for known effects of sampling design (for example, county population and household size).

2. For all results in this paragraph, analysis of variance with a Scheffe posthoc test comparing averages within each type of community demonstrates statistical significance at $\mathrm{p}<0.01$.

\section{A C K N OW LE D G M E N T S}

The authors appreciate the funding support of the National Oceanic and Atmospheric Administration (NOAA) Fisheries and the U.S. Environmental Protection Agency, as well as the support of the UNH Survey Center and the Carsey Institute.

\section{ABOUT THE AUTHORS}

Thomas Safford is an assistant professor of sociology at the University of New Hampshire and a faculty fellow at the Carsey Institute (tom.safford@unh.edu); Matthew Cutler is a Ph.D. student in sociology at the University of New Hampshire (mjcutler@unh.edu); Megan Henly is a Ph.D. student in sociology at the University of New Hampshire (megan.henly@unh.edu); Karma Norman is a social scientist with NOAA Fisheries in Seattle (karma.norman@noaa.gov); and Phillip Levin is an ecologist and senior scientist with NOAA Fisheries in Seattle (phil.levin@noaa.gov). 